\title{
AS INCUBADORAS COMO AMBIENTES DE APRENDIZAGEM DO EMPREENDEDORISMO
}

\author{
INCUBATORS AS
}

ENTREPRENEURSHIP LEARNING ENVIRONMENTS

\section{NATHALIA FIALA nathaliafiala@gmail.com}

\section{TALES ANDREASSI}

FUNDAÇÃO GETÚLIO VARGAS - ESCOLA DE ADMINISTRAÇÃO DE EMPRESAS DE SÃO PAULO

\begin{abstract}
RESUMO
Este trabalho tem como objetivo analisar as contribuições das incubadoras de negócios como agentes estimuladores da aprendizagem do empreendedorismo, por meio de um estudo qualitativo exploratório, conduzido por meio de entrevistas com estudantes de Administração que trabalhavam em incubadoras catarinenses. Como principais resultados, observou-se que o aprendizado prático do empreendedorismo adquirido no dia-a-dia da incubadora é bastante valorizado pelos estudantes, sendo essa aprendizagem fortemente baseada na troca de experiências e informações entre estudantes e empresas incubadas, encorajada pela flexibilidade, diversidade e autonomia no trabalho. O estudo reforça também a necessidade da busca de novas metodologias e ferramentas de ensino do empreendedorismo, que proporcionem um aprendizado mais efetivo e prático, e apresenta as incubadoras como um ambiente potencial ainda pouco explorado para esse fim. Palavras-chave: ensino; aprendizado; empreendedorismo; incubadora.
\end{abstract}

\section{ABSTRACT}

This main objective of this paper is to analyze the contributions of business incubators as agents for stimulating entrepreneurship learning through an exploratory qualitative study carried out through interviews with Business Administration students working in incubators, in the Brazilian state of Santa Catarina. The main results show that practical learning of entrepreneurship absorbed in the daily tasks of an incubator environment is highly valued by students, and this learning is strongly based on the exchange of experience and information between students and incubated firms, in large part due to the flexibility, diversity and autonomy experienced during the internship. This study also reinforces the need to seek out new methodologies and tools for teaching entrepreneurship, providing effective and practical learning, and presents the incubator as a potential environment that has so far been poorly explored for this purpose.

Keywords: education; learning; entrepreneurship; incubator. 


\section{INTRODUÇÃO}

O ensino do empreendedorismo é um assunto que gera bastante discussão entre os pesquisadores e educadores. No entanto, há um consenso de que o empreendedorismo possa ser ensinado ou, pelo menos, encorajado por meio da educação empreendedora (GORMAN; HANLON; KING, I997; LOPES, 20Io). Tendo isso como premissa, pode-se dizer que o foco atual das discussões sobre o tema não está mais na possibilidade de ensino, mas sim em como e com quais métodos o empreendedorismo pode ser ensinado (LOPES, 20IO).

Apesar de a educação empreendedora enfatizar o uso de metodologias nas quais o aluno aprende fazendo (LOPES, 20IO; HENRY; HILL; LEITCH, 2005; FERREIRA; MATTOS, 2003), grande parte das ferramentas e metodologias utilizadas ainda está baseada nos métodos tradicionais de ensino, os quais nem sempre possibilitam a aquisição das habilidades práticas e a experiência necessária aos empreendedores (YOUNG ${ }^{\mathrm{I}}$, 1997 apud HENRY; HILL; LEITCH, 2005).

Na busca por novas metodologias e elementos para o ensino e estímulo ao empreendedorismo, as incubadoras de negócios aparecem como um ambiente que poderia ser explorado mais intensamente para esse fim. Segundo Lavieri (2010), as incubadoras são ambientes ricos em aprendizagem, longe das salas de aula, em que ocorrem experiências enriquecedoras à educação empreendedora. Porém, são poucos os professores que utilizam as incubadoras como recurso didático para estimular o empreendedorismo entre seus alunos.

A incubadora como recurso didático pode ser explorada como local de visitas dos alunos (aproximando-os da realidade de uma empresa nascente) ou por meio de palestras com empreendedores. Assim, na incubadora o aluno pode aprender de forma indireta, pelos relatos dos empreendedores e da percepção do ambiente empreendedor. No entanto, a incubadora ou

1 YOUNG, J. E. Entrepreneurship education and learning for university students and practicing entrepreneurs. In: SEXTON, D. L.; SIMLOR, R. W. Entrepreneurship 2000. Upstart Publishing, Chicago, IL., 1997. 
as empresas nela incubadas podem representar também uma forma de aprendizagem direta, ao oferecer estágio para alunos.

Nesse sentido, o trabalho tem como objetivo analisar as contribuições das incubadoras de negócios como agentes estimuladores da aprendizagem do empreendedorismo. Como objetivos específicos, podem ser citados:

Objetivo A: verificar a relação percebida pelos estudantes entre a experiência profissional na incubadora e o estímulo ao empreendedorismo;

Objetivo B: identificar as características e habilidades desenvolvidas nos estudantes durante a experiência profissional na incubadora;

Objetivo C: descrever como as incubadoras podem atuar como agentes estimuladores do empreendedorismo;

Objetivo D: identificar os motivos que estimularam os estudantes a procurar a incubadora de negócios para a realização do estágio;

Objetivo E: identificar se os estudantes aprendem mais por meio dos métodos formais ou informais, segundo a sua percepção.

Este trabalho está estruturado em sete partes, além desta introdução. As três partes iniciais referem-se à revisão da literatura, abordando-se a educação empreendedora e o processo de empreender, seguida pela aprendizagem empreendedora e finalizada pela análise da incubadora como um ambiente de aprendizagem. A seguir, relata-se a metodologia utilizada e apresentam-se os resultados alcançados. Por fim, estabelecemse as conclusões do trabalho, sendo seguidas pelas referências utilizadas. 


\section{EDUCAÇÃO EMPREENDEDORA E O PROCESSO DE EMPREENDER}

A expressão "educação empreendedora" apresenta uma série de definições na literatura. Para Hynes e Richardson (2007), educação empreendedora não se refere apenas a educar as pessoas para abrirem seus negócios, mas tem também a função de desenvolver nos alunos habilidades, conhecimentos e competências para que eles possam atuar no ambiente de trabalho de forma mais empreendedora, inovadora e flexível. Para tanto, o aprendizado nos programas de empreendedorismo deve ser baseado em situações reais, para que se possa melhor implantar o que foi aprendido (HENRY; HILL; LEITCH, 2005). No entender de Rabbior (I990), um efetivo programa de educação empreendedora tem base na engenhosidade, na inovação e na inspiração do educador, e deve ser adaptado às necessidades, circunstâncias e oportunidades.

O relatório da União Europeia de 2003 (Comission of the European Communities, 2003) demonstra que, dos $37 \%$ dos europeus que estão pensando ou já decidiram se tornar um empreendedor, apenas $15 \%$, de fato, empreendem. As pesquisas indicam que saber como iniciar um negócio aumenta a probabilidade da pessoa se tornar um empreendedor, e que as pessoas que foram expostas ao empreendedorismo anteriormente, por meio de amigos, família ou da educação, têm maior probabilidade de considerar, de fato, em começar seu próprio negócio.

Scott e Twomey (1988) realizaram um estudo com universitários dos Estados Unidos, Inglaterra e Irlanda sobre suas atitudes em relação à carreira. O estudo demonstrou que estudantes que possuíam pais empreendedores apresentavam maior preferência para abrir seu próprio negócio e menor preferência em trabalhar para grandes empresas. Nesses casos, os pais empreendedores tinham uma dupla influência: além de servirem de modelos para seus filhos, eram vistos também como provedores de recursos.

Os fatores mencionados nesses dois estudos relacionados à decisão de empreender estão presentes no modelo de processo empreendedor desenvolvido por Bygrave (2004). Em seu modelo, Bygrave (2004) explica a criação de uma empresa por meio de fatores pessoais, sociológicos e 
ambientais. O modelo começa com a ideia do negócio, seguido por um evento que irá impulsionar seu início, a implantação e o crescimento. A Figura I ilustra o modelo de Bygrave (2004).

Figura I Modelo de processo empreendedor

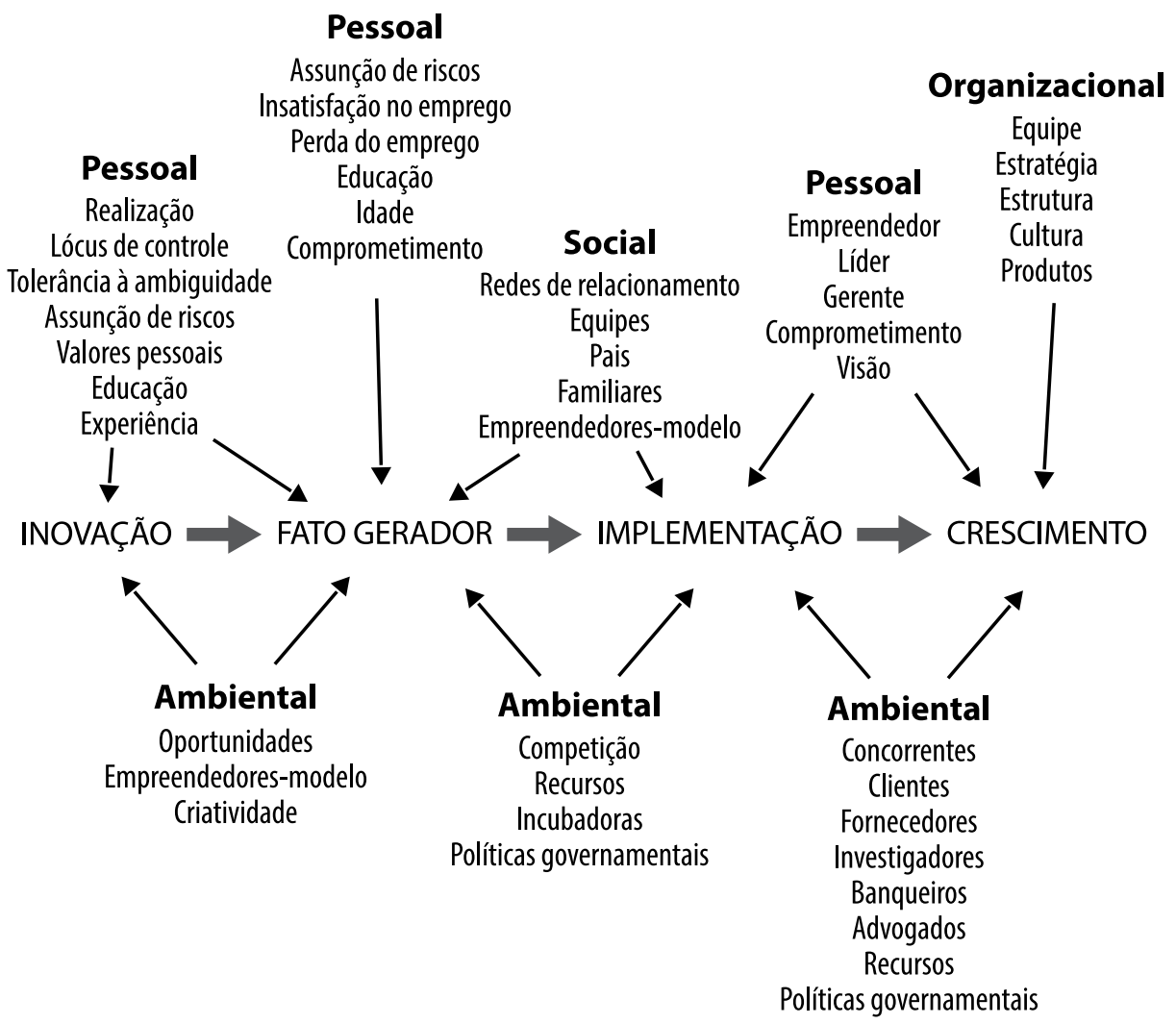

Fonte: Bygrave (2004).

Para Bygrave (2004), quando uma pessoa possui uma ideia para abrir um negócio, fatores como perspectivas alternativas de carreira, família, amigos, empreendedor-modelo, situação da economia e disponibilidade de recursos são decisivos para definir se ela realmente buscará transformar essa ideia em um negócio. Quase sempre há um fato que irá originar o nascimento 
da empresa: o empreendedor pode não vislumbrar melhores perspectivas de carreira, ter perdido uma promoção ou ter sido despedido, por exemplo. No entanto, para algumas pessoas, o empreendedorismo é uma escolha de carreira deliberada.

Quanto aos fatores que influenciam a decisão de empreender, Bygrave (2004) afirma que os traços empreendedores são moldados pelos atributos da personalidade e pelo ambiente. Ao citar o ambiente, o autor menciona que os empreendedores-modelo também são importantes, porque conhecer alguém que teve sucesso empreendendo faz com que seja muito mais real e concreta a possibilidade de se tornar um empreendedor. $\mathrm{O}$ autor relata também que a maioria das pessoas que deseja seguir a carreira empreendedora entra em contato com esses empreendedores-modelo primeiramente em casa ou no trabalho.

No que diz respeito aos fatores sociológicos que influenciam os empreendedores, Bygrave (2004) cita, além dos empreendedores-modelo, as responsabilidades com a família como tendo um papel importante na decisão de começar um negócio, bem como a rede de relacionamentos, fundamental para o empreendedor. Bygrave (2004) menciona as incubadoras de negócios como fatores ambientais que favorecem o empreendedorismo. Não só as incubadoras, mas também instituições de apoio e universidades podem ajudar os empreendedores a formular seu plano de negócio e fornecer o necessário para que ele possa empreender.

\section{APRENDIZAGEM EMPREENDEDORA}

Cope (2005) define a aprendizagem empreendedora como "um processo dinâmico de conscientização, reflexão, associação e aplicação" (p. 387). Para o autor, a questão principal é que a utilização do aprendizado empreendedor pode ocorrer muito tempo depois da experiência em si. Para Politis (2005), a aprendizagem empreendedora é um processo experiencial, no qual a experiência pessoal é transformada em conhecimento que, por sua vez, serve como guia para a escolha de novas experiências.

A aprendizagem pode ocorrer de maneira formal, informal ou nãoformal (ANTONELLO, 2005; SCHUGURENSKY, 2000). A educação formal refere-se aos 
níveis ou graus de conhecimento adquiridos em uma instituição, desde a pré-escola até a graduação. Esse sistema possui um currículo definido, objetivos e mecanismos de avaliação explícitos e professores qualificados e certificados (SCHUGURENSKY, 2000).

A educação não formal engloba os programas educacionais organizados fora do sistema educacional formal, e são normalmente de curta duração e voluntários, como cursos de inglês ou aulas de ioga. Assim como na educação formal, há a figura do professor (muitas vezes como um instrutor ou facilitador) e um currículo com níveis de aprendizado. Porém, os programas de educação não formal geralmente não exigem escolaridade como pré-requisito (sCHUGU RENSKY, 2000).

Schugurensky (2000) define a aprendizagem informal como a aprendizagem que está fora dos currículos das instituições e programas educacionais formais e não formais. O autor ressalta o uso do termo "aprendizagem" ao tratar da aprendizagem informal, e não o termo "educação", porque na aprendizagem informal não há instituições educacionais, professores ou currículo. Além disso, o autor ressalta que a aprendizagem informal ocorre fora dos currículos das instituições educacionais, e não fora dessas instituições, podendo a aprendizagem ocorrer também dentro das instituições de educação formal e não formal. Nos casos em que a aprendizagem informal ocorre dentro dessas instituições, ela ocorre de maneira independente e às vezes até contrária aos objetivos do currículo.

Livingstone (1999) ressalta a necessidade de distinguir a aprendizagem informal explícita das percepções diárias, socializações e outras aprendizagens tácitas. A aprendizagem informal explícita requer o reconhecimento consciente da atividade como sendo uma atividade de aprendizagem significativa. $\mathrm{O}$ que distingue a aprendizagem informal explícita, portanto, é a identificação tanto de uma nova forma de conhecimento, entendimento ou habilidade adquirida por iniciativa própria, quanto do processo de aquisição (LIVINGSTONe, I999). As aprendizagens tácitas que ocorrem no dia-a-dia não são reconhecidas como aprendizagem formal explícita. Nesses casos, a aprendizagem está tão incorporada a outras 
atividades e relações entre as pessoas na sua vida social que fica difícil distingui-las como aprendizagem (LIVINGSTONE, I999).

O psicólogo americano David Kolb desenvolveu um modelo de como as pessoas aprendem, chamado Modelo de Aprendizagem Vivencial. Esse modelo enfatiza o papel das experiências no aprendizado. Segundo Kolb (1997), o processo de aprendizagem possui duas dimensões básicas. A primeira delas apresenta, de um lado, a experiência concreta e, do outro, a conceituação abstrata. A segunda dimensão possui a experimentação ativa em um lado e a experimentação reflexiva em outro. Não existe o lado bom ou ruim nas dimensões. Ou seja, o indivíduo deve se envolver em novas experiências, refletir e observá-las sob diferentes perspectivas, criando conceitos que transformem suas observações em teoria, e utilizando-a para a resolução de problemas e tomada de decisão.

No decorrer da vida, as pessoas acabam utilizando determinadas habilidades de aprendizagem e deixando de utilizar outras. Isso ocorre devido às experiências pelas quais as pessoas passam, as características hereditárias e as exigências do ambiente onde estão inseridas (KOLB, 1997). Essa afirmação de Kolb (1997) poderia explicar, de certa forma, o que Bygrave (2004) propõe em seu modelo. Para ele, o fato de a pessoa possuir pais empreendedores que, além de servirem como modelo, irão proporcionarlhe um ambiente que estimule as habilidades específicas e características empreendedoras, faz com que as chances dela empreender futuramente sejam maiores do que a das pessoas que não possuem pais empreendedores.

No modelo proposto por Kolb, percebe-se que o aprendizado efetivo não ocorre sem a experimentação concreta, ou seja, sem que a pessoa vivencie a experiência. Dessa forma, pode-se dizer que o aprendizado do empreendedorismo também deve ter uma etapa que permita ao aprendiz experimentar situações que lhe possibilitem desenvolver características e habilidades empreendedoras.

Segundo Lopes (2010), a educação empreendedora enfatiza o uso de metodologias de ensino nas quais o aluno aprende fazendo ("learning by doing"). Nessas situações de aprendizagem, o aluno defronta-se com "eventos críticos que o forçam a pensar de maneira diferente, buscando 
saídas e alternativas, ou seja, aprendendo com a experiência, com o processo" (LOPES, 20IO, p. 29). Por essa razão, os autores entendem que a educação empreendedora está relacionada à aprendizagem vivencial de Kolb.

\section{INCUBADORA COMO UM AMBIENTE DE APRENDIZAGEM}

Dentre os ambientes utilizados para o ensino do empreendedorismo está a incubadora de negócios. Para Vedovello e Figueiredo (2005), as incubadoras fornecem às empresas incubadas instalações físicas adequadas e de qualidade, além de serviços de apoio compartilhados entre as empresas e aconselhamento sobre o funcionamento do mercado, tecnologias e viabilidade de apoio financeiro. Seu objetivo é explorar e potencializar os recursos existentes e incentivar a sinergia entre os pares. Buscam também criar um ambiente favorável ao surgimento e fortalecimento de novos negócios, fazendo com que as empresas incubadas se transformem em empresas graduadas e bem sucedidas.

Lavieri (20I0) destaca as incubadoras como espaços em que ocorrem experiências enriquecedoras à educação empreendedora. O autor enfatiza que, geralmente, as incubadoras têm contato com as universidades, mas esse contato limita-se a suas áreas de pesquisa. Segundo Lavieri (20I0), são poucos os professores que utilizam as visitas às incubadoras como recurso didático, para que o aluno conheça a prática da inovação e as dificuldades que os empreendedores enfrentam. Já Kirby (2004) refere-se às incubadoras como laboratórios de aprendizagem do empreendedorismo, por meio das quais o aluno pode testar os conceitos aprendidos em aula em situações novas, adquirindo assim experiência concreta. 


\section{METODOLOGIA}

O presente estudo possui natureza eminentemente exploratória, haja vista os poucos estudos existentes sobre o tema (COLLIS; HUSSEY, 2005). Em relação ao método, a pesquisa é considerada qualitativa. Para Godoy (I995), a pesquisa qualitativa parte de focos de interesse ou de questões amplas, que se vão definindo no decorrer do estudo. Não procura medir ou enumerar os eventos em estudo, nem utiliza instrumentos estatísticos para análise dos dados. Segundo Gibbs (2009), a pesquisa qualitativa busca entender, descrever e, por vezes, explicar os fenômenos sociais “de dentro”, de várias maneiras.

Para o desenvolvimento da pesquisa, inicialmente, os autores fizeram uma revisão bibliográfica sobre os assuntos pertinentes ao estudo, que serviu como subsídio para o desenvolvimento do instrumento de coleta de dados. Para a coleta propriamente dita, os autores utilizaram entrevistas semiestruturadas, que visavam obter o máximo de informações sobre os tópicos abordados na pesquisa, por meio de relatos orais dos respondentes. A opção pela realização de entrevistas foi feita por acreditar-se que esta forma é a que mais se adequava ao estudo proposto e a que traria resultados mais ricos e detalhados. Foram realizadas duas entrevistas como pré-testes, e com base nelas, foram feitas as alterações necessárias no roteiro de entrevista.

O estudo foi realizado com nove estudantes de Administração de Empresas que trabalhavam há pelo menos três meses nas incubadoras catarinenses. Tais entrevistas ocorreram, em sua grande maioria, em incubadoras de base tecnológica, embora algumas entrevistas tenham sido realizadas em incubadoras tradicionais. Todas as incubadoras consideradas no trabalho possuíam empresas instaladas fisicamente, não tendo sido consideradas incubadoras virtuais.

As entrevistas aconteceram entre dezembro de 2010 e dezembro de 20II, e foram gravadas com as devidas autorizações. Visando assegurar o anonimato dos entrevistados, no decorrer do estudo será utilizado o gênero masculino para referir-se aos estudantes.

A análise dos dados obtidos nas entrevistas foi realizada por meio da técnica da análise de conteúdo. Para Bardin (20I0), análise de conteúdo é um 
conjunto de técnicas de análise que visa obter, por meio de procedimentos sistemáticos, indicadores - quantitativos ou não - que permitam a inferência de conhecimentos por meio das mensagens (neste caso, as entrevistas). Godoy (1995) afirma que a análise de conteúdo é um "instrumento metodológico que pode ser aplicado a discursos diversos e a todas as formas de comunicação, seja qual for a natureza de seu suporte" (GODOY, 1995, p. 23). A técnica de análise de conteúdo parte do pressuposto de que, por trás do discurso aparente, há um sentido escondido a ser desvendado. O esforço do analista é duplo: ele deve tentar entender o sentido da comunicação como um receptor normal, além de desviar o olhar para buscar outros significados, outras mensagens que podem ser enxergadas por meio da mensagem original.

Para este estudo, após a realização e gravação das entrevistas e sua posterior transcrição, os relatos escritos foram validados junto aos entrevistados. Com as transcrições revisadas e aprovadas pelos entrevistados, deu-se início à análise de conteúdo propriamente dita. Para tanto, foram definidas cinco categorias de análise, as quais são entendidas como rubricas ou classes que reúnem um grupo de elementos sob um título genérico, agrupamento esse que se deu em razão dos caracteres comuns desses elementos (Bardin, 20I0). Para este trabalho, as categorias de análise foram definidas para refletir os cinco objetivos específicos do estudo, a saber: incubadora como fonte de estímulo ao empreendedorismo, impacto da experiência na incubadora, incubadora como agente estimulador do empreendedorismo, motivos que levam à experiência na incubadora e formas de aprendizagem. 


\section{RESULTADOS E DISCUSSÃO}

Os resultados obtidos na análise de conteúdo das entrevistas serão apresentados por meio da retomada dos objetivos específicos.

\section{A - INCUBADORA COMO FONTE DE ESTÍMULO AO EMPREENDEDORISMO}

O objetivo específico A consistia em verificar a relação percebida pelo estudante entre a experiência profissional na incubadora e o estímulo ao empreendedorismo, evidenciado pela intenção empreendedora. Esse objetivo foi alcançado.

Nenhum dos nove entrevistados havia aberto um negócio até a data da entrevista. Cinco deles afirmaram ter a intenção de abrir um negócio, dois disseram não querer abrir e outros dois não descartaram totalmente a ideia de empreender, mas o fariam apenas sob determinadas circunstâncias (em sociedade com um parente, por exemplo). Os dois entrevistados que mencionaram não possuir intenção de empreender não possuem pais empreendedores (um deles possui tios e primos empreendedores). Já os dois entrevistados que disseram ter intenção de empreender em circunstâncias específicas possuem pais empreendedores. Dentre os cinco estudantes que mencionaram que desejam empreender, quatro deles possuem pais empreendedores, enquanto o outro não possui nenhum empreendedor na família. Esses resultados vão ao encontro da literatura, que encontra uma correlação positiva entre a intenção de empreender e o fato de se ter parentes próximos empreendedores, conforme relatado por Bygrave (2004) e Scott e Twomey (1988).

Questionados sobre o que os influenciou nessa intenção de empreender, dos cinco entrevistados que disseram querer abrir um negócio, apenas um deles afirmou que não sofreu nenhuma influência de fatores externos (como a incubadora ou a faculdade), mas admite que a faculdade o auxiliou a definir melhor o negócio que deseja abrir. A incubadora foi citada como responsável pela intenção de empreender por três desses cinco entrevistados, sendo que um deles afirmou que a incubadora foi a única influência que 
teve, outro mencionou que a faculdade também o influenciou, e o terceiro citou também as experiências profissionais anteriores. Apenas um estudante que possui a intenção de empreender e percebeu ter sido influenciado nessa intenção não mencionou a incubadora como influenciadora, citando apenas a faculdade e as experiências profissionais anteriores.

Ao mencionar a incubadora como influenciadora da intenção de empreender, além da questão do encorajamento pela percepção do empreendedorismo na prática (possibilidade de sucesso, não é tão difícil como se aprende na faculdade, etc.), a questão do conhecimento dos projetos de fomento a novos negócios também foi um ponto citado para explicar de que forma se deu a influência da incubadora na formação dessa intenção.

Vale ressaltar que nenhum dos entrevistados citou os pais ou familiares empreendedores como influenciadores na intenção de empreender, muito embora a maioria deles tivesse pais empreendedores, conforme observado anteriormente. Aliás, um dos entrevistados mencionou que, justamente por possuir pais e familiares empreendedores, sabe como é difícil abrir e manter um negócio lucrativo e, por essa razão, não tem, a princípio, intenção de empreender.

Um dos entrevistados fez uma crítica ao distanciamento da universidade e da incubadora, e mencionou o fato de que, se os alunos conhecessem melhor a incubadora, poderiam despertar essa vontade de empreender. Tal comentário está coerente com os achados de Lavieri (2010), que relatou o baixo número de professores que se utilizam da incubadora como recurso didático.

[...] antes eu até pensava em abrir alguma coisa, mas nunca fiquei com aquela vontade. Só que depois, dentro da incubadora, você vendo que dá certo, que muitos saíram daqui e estão super bem, é aquela coisa... que você tá fazendo uma coisa sua, não pra outra pessoa, acho que isso que despertou mais o interesse. Até na faculdade, assim, a gente vê que os alunos, eles não pensam muito nisso, então talvez se eles abrissem melhor a mente, se eles conhecessem melhor a incubadora, talvez eles também teriam essa visão[...] (Entrevistado D). 
Os entrevistados foram questionados também sobre a existência de empreendedores-modelo, ou seja, alguém em quem se inspirariam caso abrissem um negócio. Apenas cinco dos entrevistados citaram possuir empreendedores-modelo, e todos estavam associados a empresas incubadas (três casos) ou já graduadas (dois casos). Nenhum estudante citou os pais ou familiares empreendedores como modelos.

\section{B - IMPACTO DA EXPERIÊNCIA NA INCUBADORA}

O segundo objetivo específico era identificar os aspectos desenvolvidos nos estudantes durante a experiência profissional na incubadora. Esse objetivo também foi alcançado. Os sete pontos citados por dois entrevistados cada, uma vez que não houve pontos citados por mais de dois entrevistados, foram os seguintes:

- Aumento da responsabilidade que lhes é atribuída no trabalho na incubadora em relação às experiências anteriores.

- A equipe na qual trabalhavam era formada somente pelo estudante e por seu chefe. O chefe era quem administrava a incubadora e dava o apoio aos incubados. Cabia ao estudante auxiliá-lo nessa tarefa. Assim, além do estudante se sentir responsável, sentia também que tinha autonomia para executar as ações necessárias.

- O desenvolvimento da comunicação.

- O encorajamento e o fortalecimento da intenção de empreender, pois na incubadora eles puderam enxergar o empreendedorismo como opção de carreira, e perceber que, apesar das dificuldades e do esforço necessário, é possível abrir um negócio e fazê-lo dar certo. O trecho a seguir ilustra esse ponto.

[...] Eu quero montar uma empresa pra mim, e aí, eu sentia esse medo. E agora eu vendo aqui, to vendo que não é tão difícil assim, né, a partir do momento que tu quer uma coisa mesmo, tu tem que... como o pessoal tá fazendo, a gente vê o trabalho que eles passam, mas não é um bicho de sete cabeças. É possível. (Entrevistado C).

- A percepção e a consciência dos pontos que precisavam melhorar para crescerem profissionalmente. E, juntamente com isso, a 
percepção também de seu desenvolvimento ao longo da experiência na incubadora.

- Ampliação dos conhecimentos, não somente na parte técnica, como mencionado anteriormente, mas de maneira mais ampla, até modificando conhecimentos que eles já possuíam. Isso pode ser observado no trecho abaixo, e de certa forma nos remete à visão da incubadora como um laboratório de aprendizagem, conforme defendido por Kirby (2004).

[...] Eu estou ampliando meu conhecimento, e eu estou aprendendo a lidar com algumas dificuldades. Eu aprendi... digamos... a diferenciar algumas coisas do mundo dos negócios:[...] quando a pessoa é só funcionário, ela não consegue enxergar o caminho de quem é o proprietário, então eu estou conseguindo fazer essa separação... vendo essas diferenças. E também a cada dia eu descubro que sou capaz de algo a mais que eu não sabia que eu era, sempre a gente descobre, vai descobrindo... (Entrevistado F).

- A oportunidade de o estudante conhecer, no ambiente da incubadora, diferentes áreas de uma empresa, empresas de diferentes ramos e pessoas desempenhando diversas funções.

Ao falar sobre sua experiência profissional, seis entrevistados mencionaram uma relação entre a prática vivenciada nas incubadoras e o aprendizado adquirido na Faculdade. Isso pode ser observado no trecho seguinte, o qual está condizente com o que foi defendido por Lopes (2010), quando enfatiza a importância do uso de metodologias nas quais o aluno aprende fazendo.

[...] A incubadora é uma extensão, assim, pra mim, eu acho, da universidade, porque ali é a prática, a gente tá vendo... desde como formalizar uma empresa... [...] com os problemas, como montar um plano de negócios, porque na universidade a gente aprende ali no papel, tá ali, mas na prática é bem melhor. (Entrevistado C).

Os entrevistados criticaram o distanciamento entre a Universidade e a prática das empresas, e a falta de atividades curriculares que permitam ao aluno do curso de Administração conhecer na prática a teoria adquirida em sala de aula durante a Faculdade. Isso pode ser observado no trecho a seguir. 
[...] Tem coisas na universidade que você só ouve de nome: ah, um plano de negócio, um plano de marketing, então você aprende isso só no nome, e aí, de acordo com o que você escolhe pra fazer o trabalho de conclusão de estágio, é que você vai se aprofundar [...]. E aqui não, aqui a gente é obrigada a saber tudo isso, então... é no cotidiano. [...] quem às vezes está na faculdade não tem noção de como funciona uma empresa, e aqui a gente consegue ter esse conhecimento: de como funciona uma empresa, do que ela precisa, quais são as dificuldades, desde o início ... (Entrevistado F).

\section{C - INCUBADORA COMO AGENTE ESTIMULADOR DO EMPREENDEDORISMO}

O objetivo C consistia em descrever como as incubadoras podem atuar como agentes estimuladores do empreendedorismo. Os estudantes mencionaram que o principal aspecto da incubadora como estimuladora do empreendedorismo é o encorajamento. Na sala de aula os alunos viam o empreendedorismo como algo muito difícil, quase como se não fosse possível ter sucesso por meio dele. Eles acabavam não considerando o empreendedorismo como opção de carreira, pois a Faculdade salientava muito mais seus aspectos negativos e suas dificuldades. Ao trabalhar na incubadora, os estudantes perceberam que, apesar de serem necessárias muita persistência e determinação, é possível empreender, ter sucesso e lucrar com seu próprio negócio. Tal resultado está alinhado com os estudos de Politis (2005), para quem a aprendizagem empreendedora é um processo experiencial, no qual a experiência pessoal é transformada em conhecimento.

Além disso, os estudantes passaram a enxergar a incubadora como um apoio a quem quer empreender, pois praticamente nenhum deles tinha ouvido falar de incubadora antes. Só depois de estarem na incubadora perceberam seu papel e importância para quem quer abrir um negócio: baixo custo, apoio por meio das consultorias, maior facilidade de acesso a financiamentos e auxílio no desenvolvimento e implantação do plano de negócios. Quando questionados sobre por que utilizariam as incubadoras para abrir um negócio, a rede de relacionamento também foi lembrada 
pelos estudantes como um aspecto positivo que a incubadora oferece ao empreendedor.

A possibilidade de conhecimento prático do empreendedorismo e seu consequente encorajamento, aliado às facilidades e apoio que a incubadora oferece aos incubados demonstra como ela pode atuar como um agente estimulador do empreendedorismo nos estudantes de Administração. Com isso, o objetivo C também foi atingido.

\section{D-MOTIVOS QUE LEVAM À EXPERIÊNCIA NA INCUBADORA}

$\mathrm{O}$ objetivo $\mathrm{D}$ relacionava-se à identificação dos motivos que estimularam o estudante a procurar a incubadora de negócios para realizar uma experiência profissional. Percebeu-se que em nenhum dos casos houve uma escolha realmente deliberada em relação à incubadora para ter sua experiência profissional. Oito dos nove estudantes entrevistados estavam desempregados e, ao buscar oportunidades de emprego, surgiu a incubadora como uma delas. Apenas um dos estudantes estava trabalhando em outra empresa quando soube da vaga na incubadora por meio de um amigo, e acabou deixando seu emprego para trabalhar na incubadora. Vale ressaltar o caso de um estudante que foi selecionado, ao mesmo tempo, para trabalhar na administração da incubadora e em outra empresa não incubada, e disse que optou pela incubadora, por acreditar que a experiência seria mais enriquecedora, uma vez que teria contato com várias empresas. Essa escolha foi feita depois de conversar com a coordenadora da incubadora e pesquisar na Internet sobre o assunto, pois o mesmo também não tinha conhecimento sobre o que era e como funcionava uma incubadora.

Esses resultados sugerem que há a necessidade de maior divulgação das incubadoras catarinenses, começando pelo próprio ambiente acadêmico, onde se presume que haja maior liberdade para fazer essa inserção, uma vez que as incubadoras ou encontram-se no próprio campus universitário, ou têm parcerias com professores que auxiliam nos projetos e consultorias. Diante do exposto, considera-se que esse objetivo também foi atingido. Tais resultados novamente vêm reforçar o que foi encontrado por Lavieri (20I0), relativo a pouca utilização das incubadoras como recurso didático. 


\section{E - FORMAS DE APRENDIZAGEM}

O quinto objetivo era identificar se os estudantes aprendem mais por meio dos métodos formais ou informais, segundo sua percepção. Todos os sete respondentes a essa questão afirmaram que, na incubadora, aprendem na prática. Isso inclui as situações novas que aparecem constantemente no diaa-dia e com as quais eles precisam lidar, além da aplicação do conhecimento adquirido na Faculdade, acarretando um aprendizado constante. Outro ponto, citado por quatro dos sete respondentes para explicar como aprendem nas incubadoras, refere-se ao aprendizado que advém do contato com as empresas e pessoas, por meio da troca de informações e experiências.

Durante a entrevista, os estudantes foram indagados sobre o que a incubadora oferecia que lhes permitia aprender. Seis entrevistados responderam a esse questionamento, sendo que três deles citaram a liberdade como responsável pelo aprendizado na incubadora. Essa liberdade está associada tanto a questões mais operacionais, como a liberdade de horário e o prazo de execução das tarefas, quanto à liberdade para buscar novos desafios e, assim, aprender e crescer profissionalmente. O segundo fator apontado por dois estudantes foi a diversidade de situações, pessoas e empresas, que leva ao aprendizado. Por fim, um dos estudantes apontou a autonomia para tomar decisões como fator de destaque para o aprendizado.

Questionados se há diferenças entre o aprendizado na incubadora e na sala de aula, seis dos sete respondentes a essa questão afirmaram que os dois aprendizados são muito diferentes, e apenas um deles mencionou que embora haja diferenças, os dois aprendizados são muito próximos, pois o que é aprendido na Faculdade é colocado em prática na incubadora, e o que é realizado na incubadora tem como base a teoria que se aprende na Faculdade.

Os seis entrevistados que afirmaram que os aprendizados são diferentes demonstraram haver uma superioridade no aprendizado ocorrido na incubadora. Isso porque, ao colocar em prática na incubadora o que foi aprendido em sala de aula, percebe-se que o conhecimento adquirido não foi suficiente ou está distante de como as coisas, de fato, acontecem. Percebe-se, no relato seguinte, a exaltação do aprendizado na prática. Tais resultados 
corroboram os estudos de Lopes (2010), Henry, Hill e Leitch (2005) e Ferreira e Mattos (2003), que reforçam a importância da utilização de metodologias em que o aluno aprende fazendo. “[...] O papel aceita tudo...Tudo que está no papel é papel, e aqui já é diferente, é diferente. É uma exceção, no caso, tu aprendes como fazer, e aqui tu fazes as coisas, e nem sempre estão bem de acordo." (Entrevistado C).

Três estudantes afirmaram que aprendem mais na incubadora - por meio de métodos informais, enquanto quatro disseram aprender igualmente na sala de aula e na incubadora - em função de métodos formais e informais concomitantemente, e que os dois aprendizados andam juntos e se complementam. Ninguém afirmou que o aprendizado na sala de aula é superior ao aprendizado na incubadora.

Dessa forma, a opinião dos entrevistados sugere que se aprende mais pelo método informal, ou combinando o método informal com o formal. Mas somente o método formal parece não ser suficiente para o aprendizado e estímulo ao empreendedorismo, fato esse comprovado também por Kolb (I997) em seu modelo de aprendizagem vivencial. Assim, pode-se dizer que esse objetivo também foi alcançado.

O Quadro I resume os principais resultados encontrados no trabalho:

Quadro I Síntese dos resultados encontrados

\begin{tabular}{|ll|}
\hline $\begin{array}{l}\text { Categorias de análise } \\
\text { Incubadora como } \\
\text { fonte de estímulo ao } \\
\text { empreendedorismo }\end{array}$ & $\begin{array}{l}\text { Resultados } \\
\text { empreender, principalmente em função do conhecimento dos } \\
\text { projetos de fomento a novos negócios }\end{array}$ \\
\hline $\begin{array}{l}\text { Impacto da experiência na } \\
\text { incubadora }\end{array}$ & $\begin{array}{l}\text { O impacto se dá principalmente no encorajamento e } \\
\text { fortalecimento da intenção de empreender, além de ampliar e até } \\
\text { mesmo modificar o conhecimento que os pesquisados possuíam }\end{array}$ \\
\hline $\begin{array}{l}\text { Incubadora como } \\
\text { agente estimulador do } \\
\text { empreendedorismo }\end{array}$ & $\begin{array}{l}\text { Pesquisados percebem a viabilidade de se tornar um } \\
\text { empreendedor e a importância do apoio de uma incubadora }\end{array}$ \\
\hline $\begin{array}{l}\text { Motivos que levam à } \\
\text { experiência na incubadora }\end{array}$ & $\begin{array}{l}\text { Os motivos são, na maioria, casuais. Há necessidade de maior } \\
\text { divulgação da atuação das incubadoras, começando pelo próprio } \\
\text { ambiente acadêmico }\end{array}$ \\
\hline Formas de aprendizagem & $\begin{array}{l}\text { Aprendizagem é fortemente baseada na troca de informações e } \\
\text { experiências, encorajada pela flexibilidade das tarefas, diversidade } \\
\text { de situações e autonomia na tomada de decisões }\end{array}$ \\
\hline
\end{tabular}




\section{CONSIDERAÇÕES FINAIS}

Os resultados alcançados neste estudo vão além dos propostos nos objetivos. Por meio da interação com os entrevistados, os autores puderam perceber algumas características pessoais dos estudantes que estavam presentes em suas atividades na incubadora.

A principal característica observada é o grande sentimento de fazer parte do negócio. Os estudantes falavam das empresas nas quais trabalhavam como se também fossem seus donos: sentiam-se responsáveis pelo seu sucesso, e estavam totalmente comprometidos com os resultados. Essa visão que os estudantes demonstraram possuir é bem diferente do que se observa em outras organizações fora da incubadora onde, em geral, eles têm poucas responsabilidades, realizam atividades mais simples, não se envolvem em questões estratégicas e nem possuem muita liberdade para expor suas ideias. Os estudantes entrevistados passavam a sensação de respeito e admiração pelos empreendedores - seus superiores - mas, ao mesmo tempo, tinham um relacionamento muito próximo e aberto com eles (incentivados a expressar e defender suas próprias opiniões).

A busca do aprendizado constante também foi percebida pelos autores nos estudantes entrevistados. Eles pareciam não ver obstáculos quando tinham a necessidade de aprender algo novo: buscavam o conhecimento na Faculdade, com os professores, colegas de trabalho ou mesmo pela Internet.

Ao mesmo tempo em que se observaram essas características positivas nos estudantes, podia-se também perceber a falta de valorização à incubadora por outros públicos. As universidades e instituições apoiadoras/ mantenedoras das incubadoras parecem não enxergar o valor que elas têm para a comunidade e como podem ser exploradas para o ensino. Algumas delas ficam em locais escondidos, de difícil visualização, junto a algum outro órgão/setor na universidade onde há disponibilidade de espaço. Ao mesmo tempo em que algumas incubadoras estão instaladas fisicamente nas dependências das universidades, parecem estar a uma distância imensa das atividades e do mundo universitário e, com isso, dos estudantes. 
Trata-se de um ambiente onde a liberdade e a diversidade levam a um aprendizado na prática, que permite ao estudante assumir responsabilidades, ter autonomia para tomar decisões e aprender com isso, desenvolver as habilidades de comunicação e fazer nascer ou crescer ainda mais a intenção de empreender. Um ambiente no qual o aprendizado ocorre baseada na percepção das próprias fraquezas e limitações e da busca em minimizá-las ao máximo; onde o contato com empresas, áreas e pessoas tão diferentes traz um real aprendizado.

E nesse ambiente da incubadora os estudantes encontram um ponto de apoio e, ao mesmo tempo, alguém para admirar: o empreendedor. Aprendem com ele, no dia-a-dia, a ter determinação e persistência, a inovar sempre, a reconhecer os erros e fraquezas. Também que é preciso ter coragem, confiança e assumir riscos, e que a dedicação e o esforço são essenciais quando se quer atingir um objetivo. Aprendem tentando, errando e acertando.

Este trabalho representa um primeiro esforço para entender a visão dos estudantes sobre o papel da incubadora no aprendizado do empreendedorismo. Por meio desse entendimento, pode-se pensar em maneiras de aproveitar melhor a incubadora como recurso didático a ser utilizado pelas instituições de ensino.

A valorização da complementaridade do aprendizado teórico e prático pelos estudantes ficou evidenciada neste estudo, bem como a insuficiência do ensino teórico para a aprendizagem do empreendedorismo. Isso reforça a necessidade de levar o ensino para além das salas de aula, promovendo um aprendizado, de fato, mais efetivo. Se os próprios alunos já percebem a necessidade e os benefícios dessa aliança entre o prático e o teórico, o primeiro passo para a mudança já está dado.

Para finalizar o trabalho, citam-se como limitações do estudo, primeiramente, a abrangência da amostra, que englobou somente o Estado de Santa Catarina, e somente estudantes de Administração. Outros estudos podem ser realizados em outras regiões do país e até mesmo fora dele, bem como com estudantes de outros cursos. Outra limitação refere-se ao aspecto temporal. Foi realizada apenas uma entrevista com cada estudante. Seria 
interessante a realização de um estudo longitudinal, explorando a questão da intenção de empreender versus a ação de empreender de fato. Ou seja, esses mesmos estudantes poderiam ser abordados daqui a cinco ou dez anos para verificar se os que possuíam a intenção de empreender de fato empreenderam, ou se a intenção surgiu em quem afirmou não possuí-la. 


\section{REFERÊNCIAS}

ANTONELLO, C. S. Articulação da aprendizagem formal e informal: seu impacto no desenvolvimento de competências gerenciais. Alcance, v. 12, n. 2, p. 183-209, 2005.

BARDIN, L. Análise de Conteúdo. 5.ed. Portugal: Edições 70, 2010.

BYGRAVE, W. D. The Entrepreneurial Process. In: BYGRAVE, W. D.; ZACHARAKIS, A. The portable MBA in entrepreneurship. Hoboken, NJ: John Wiley \& Sons, 2004, cap. 1, p. 1-27.

COLLIS, J.; HUSSEY, R. Pesquisa em Administração: um guia prático para alunos de graduação e pós-graduação. 2.ed. Porto Alegre: Bookman, 2005.

COMISSION OF THE EUROPEAN COMMUNITIES. Green Paper:entrepreneurship in Europe. Bruxelas: 2003. Disponível em: <http://eur-lex.europa.eu/LexUriServ/site/en/ com/2003/com2003_0027en01.pdf >. Acesso em: 06/01/ 2011.

COPE, J. Toward a Dynamic Learning Perspective of Entrepreneurship. Entrepreneurship Theory and Practice, v. 29, n. 4, p. 373-398, 2005.

FERREIRA, P. G. G.; MATTOS, P. L. C. L. Empreendedorismo e Práticas Didáticas nos Cursos de Graduação em Administração: os Estudantes Levantam o Problema. In:EnAnpad, 27., 2003, Atibaia. Anais... Atibaia: Anpad, 2003.

GIBBS, G. Análise de Dados Qualitativos. Porto Alegre: Artmed, 2009.

GODOY, A. S. Introdução à Pesquisa Qualitativa e suas Possibilidades. Revista de Administração de Empresas, v. 35, n. 2, p. 57-63, 1995.

GORMAN, G.; HANLON, D.; KING, W. Some research perspectives on entrepreneurship education, enterprise education and education for small business management: a ten-year literature review. International Small Business Journal, v.15, n.3, p. 56-78, 1997.

HENRY, C.; HILL, F.; LEITH, C. Entrepreneurship education and training: can entrepreneurship be taught? Part I. Education + Training, v. 47, n. 2, p. 98-111, 2005.

HYNES, B.; RICHARDSON, I. Entrepreneurship education: a mechanism for engaging and exchanging with the small business sector. Education + Training, v. 49, n. 8/9, p. 732$744,2007$.

KIRBY, D. A. Entrepreneurship Education and Incubators: Pre-incubators, Incubators and Science Parks as Enterprise Laboratories. In: IntEntCONFERENCE, n. 14, jul. 2004, Itália. Anais... Itália: University of Napoli Frederico II, 14 ${ }^{\text {th }}$ IntEnt, 2004.

KOLB, D. A. A Gestão e o Processo de Aprendizagem. In: STARKEY, K. Como as Organizações Aprendem: relatos do sucesso das grandes empresas. São Paulo: Futura, 1997, p. 321-341.

LAVIERI, C. Educação...empreendedora? In: LOPES, R. M. Educação Empreendedora. Rio de Janeiro: Elsevier-Campus, 2010, cap. 1, p. 1-16. 
LIVINGSTONE, D. W. Exploring the Icebergs of Adult Learning: Findings of the First Canadian Survey of Informal Learning Practices. Centre for the Study of Education and Work, 1999 (WALL Working Paper n. 10/1999).

LOPES, R. M. Referenciais para a Educação Empreendedora. In: LOPES, R. M. Educação Empreendedora. Rio de Janeiro: Elsevier-Campus, 2010, cap. 2, p. 17-44.

POLITIS, D. The process of entrepreneurial learning: A conceptual framework. Entrepreneurship Theory and Practice, v.29, n. 4, p. 399-424, 2005.

RABBIOR, G. Elements of a Successful Entrepreneurship/Economics/Education Program. In: KENT, C. A. Entrepreneurship Education: Current Developments, Future Direction. Quorum Books, 1990, cap. 4, p. 53-66.

SCHUGURENSKY, D. The forms of informal learning: towards a conceptualization of the field. Centre for the Study of Education and Work, 2000 (WALL Working Paper n. 19/2000).

SCOTT, M.; TWOMEY, D. Long term supply of entrepreneurs: student career aspirations in relations to entrepreneurship. Journal of Small Business Management, v. 26, n. 4, p. 5-13, 1988.

VEDOVELLO, C.; FIGUEIREDO, P. Incubadora de Inovação: que nova espécie é essa? RAE-eletrônica, v. 4, n. 1, p. 1-19, 2005. 


\title{
DADOS DOS AUTORES
}

\author{
NATHALIA FIALA^ nathaliafiala@gmail.com \\ Mestre em Administração pela FGV-EAESP \\ Instituição de vinculação: Fundação Getúlio Vargas - Escola de Administração de \\ Empresas de São Paulo \\ São Paulo/SP - Brasil \\ Áreas de interesse em pesquisa: Empreendedorismo, Ensino e Estratégia. \\ ${ }^{\star}$ Rua João Paul, 280, Bloco 2, ap. 2304 \\ Floresta Joinville/SC 89211-465
}

\section{TALES ANDREASSI tandreassi@gmail.com}

Doutor em Administração pela FEA-USP

Instituição de vinculação: Fundação Getúlio Vargas - Escola de Administração de Empresas de São Paulo

São Paulo/SP - Brasil

Áreas de interesse em pesquisa: Empreendedorismo. 